\title{
The Assistance In Developing Teaching Material For Sciences Teachers In Solok Selatan District Through Concept Review Based On Local Wisdom
}

\author{
Silvi Yulia Sari ${ }^{1}$, Hufri $^{1 *}$, Ganda Hijrah Selaras ${ }^{2}$ \\ ${ }^{1}$ Jurusan Fisika, FMIPA Universitas Negeri Padang, Padang, 25131, Indonesia \\ ${ }^{2}$ Jurusan Biologi, FMIPA Universitas Negeri Padang, Padang, 25131, Indonesia \\ *hufri_fis@fmipa.unp.ac.id
}

Diterima 5 November 2019, Disetujui 21 Maret 2020, Dipublikasikan 31 Maret 2020

\begin{abstract}
Solok Selatan district is located at an altitude of 350-430 meters above sea level. The landscape varies between lowlands, hills and highlands which are a series of Bukit Barisan mountains. Solok Selatan district is faced with complex environmental problems. The practice of illegal logging in forest areas and illegal gold mining along the Batang Hari and Batang Sangir streams on a large scale, so that the district of Solok Selatan is often hit by natural disasters. In addition this also caused damage to infrastructure and fatalities. This event was triggered by the low awareness and level of education of the community about the importance of environmental preservation. This is also shown from the level of Human Development Index (HDI) of Solok Selatan regency for 2017 which is 67.81 lower than the Province of West Sumatera which is 71.24. It can also be seen from the results of the 2016 National Examination ranking which is ranked 16th, with an average value of 49.18. The objectives of this activity and the targets set are to assist teachers in developing teaching materials through the concept review based on local wisdom. The method used consists of the observation phase, the orientation and discussion phase, the preparation phase for implementation, the implementation phase, the monitoring and evaluation stage as well as the data analysis and report stage. The instrument used was a science concept study test based on local wisdom and a questionnaire for the implementation of activities. The instrument used was a test on the concept review and local wisdom and the questionnaires for the implementation activities. The results of data analysis of the pretest and posttest, showed the average pretest score was 55.14, and the average posttest score was 67.18. From the paired t test, the significance result was $0.023<0.05$. So it can be concluded that the assistance activities in developing teaching material for sciences teachers have been able to improve the competence of science teachers in Junior High School in Solok Selatan district.
\end{abstract}

Keywords - Teaching Material, Local Wisdom. unrestricted use, distribution, and reproduction in any medium, provided the original work is properly cited. (C2017 by author and Universitas Negeri Padang.

\section{Pendahuluan}

Wilayah Kabupaten Solok Selatan terletak pada ketinggian 350-430 meter di atas permukaan laut. Bentang alamnya bervariasi antara dataran rendah, perbukitan, dan dataran tinggi yang merupakan rangkaian dari pegunungan Bukit Barisan. Saat ini Kabupaten Solok Selatan dihadapkan dengan permasalahan lingkungan yang kompleks. Praktik penebangan liar di kawasan hutan dan penambangan emas ilegal di sepanjang aliran Batang Hari dan Batang Sangir secara besar-besaran masih terus terjadi, sehingga kabupaten Solok selatan sangat sering di landa bencana Alam yang terjadi pada tahun 2016 dan 2017 kemaren selain menimbulkan kerusakan infrastruktur juga menimbulkan korban jiwa [1][2], seperti terlihat pada Gambar .1. 
Kondisi ini dipicu oleh masih rendahnya kesadaran dan tingkat pendidikan masyarakat tentang pentingya pemeliharan lingkungan. Hal ini juga ditunjukkan dari tingkat indek pembangunan manusia (IPM) Kabupaten Solok Selatan untuk tahun 2017 adalah 67,81 lebih rendah dari rata-rata IPM provinsi Sumatera Barat yaitu 71,24[3].

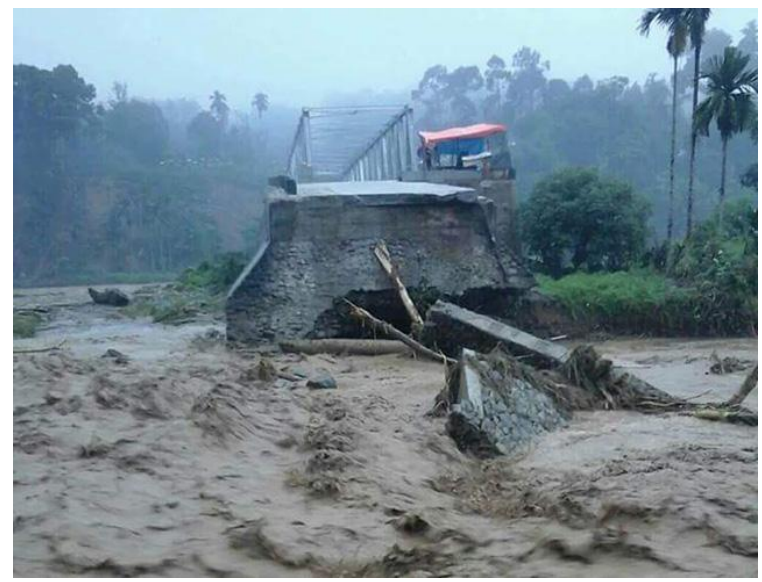

Gambar 1. Foto-foto Dahsyatnya Banjir dan

Longsor di Solok Selatan Sumbar

(batamnews.co.id)[4]

Pada bidang pendidikan Solok Selatan, juga masih tertinggal jika dibandingkan dengan Kabupaten dan Kota lain di Sumatera Barat. Masalah mendasar yang menyebabkan Solok Selatan hingga kini masih terjebak dalam perangkap ketertinggalan adalah SDM-nya sendiri seperti dinyatakan kepala Bappeda Litbang Solok Selatan, Syamsurizaldi[5]. Hal ini juga dapat dilihat dari hasil peringkat UN tahun 2016 yaitu berada pada peringkat 16 , dengan nilai rata rata komulatif untuk 4 mata pelajaran yang di UN-kan adalah 49,18[6]. Hasil ini masih jauh dari apa yang diharapkan. Berdasarkan pengamatan dan diskusi yang dilakukan dengan dengan beberapa guru dan kepala sekolah dalam pembelajaran siswa masih menunggu apa yang diberikan oleh guru.

Selanjutnya sesuai dengan Permendikbud No 103 dalam pendekatan saintifik siswa diharapkan mampu berperan aktif dalam proses pembelajaran dengan mengamati, menanya, mencoba, manalar, lalu mengkomunikasikan yang telah didapatkan dengan menanamkan karakter pada setiap siswa sehingga tercipta siswa yang kreatif dan inovatif[7]. Hal ini juga sesuai dengan hasil penelitian oleh Hufri[8], bahwa diperoleh hasil belajar siswa setelah menggunakan perangkat pembelajaran yang berbasiskan kontekstual dapat meningkatkan hasil belajar siswa.

Peningkatan kemampuan guru untuk meningkatka kualitas pembelajaran juga telah dilakukan melalui, pelatihan pengembangan multimedia berbasiskan kontekstual untuk pembelajaran inquiry bagi guru-guru SMPN 19 dan SMPN 34 Kabupaten Solok Selatan[9], Peningkatan kompetensi pedagogik guru-guru IPA SMP Solok Selatan melalui pendampingan implementasi pembelajaran kontekstual berdasarkan pendekatan saintifik[10], pengembangan media pembelajaran pada guruguru di Solok Selatan[11]. dan Peningkatan kemampuan guru-guru IPA Solok Selatan dalam mengembangkan mutimedia pembelajaran melalui penguasaan editing video[12].

Jadi dalam pembelajarannya guru hendaknya dapat mengkaitkan materi yang dipelajari dengan kondisi lokal/ kearifan lokal daerah tersebut. Untuk itu guru dapat menganalisis konsep materi IPA tersebut berbasiskan kearifan lokal. Dalam kearifan lokal terkandung prinsip lokalitas, yakni setiap daerah memiliki nilai-nilai kearifan masingmasing. Strategi pembelajaran yang baik hendaknya berangkat dari keberagaman ini. Setiap daerah wajib menempatkan nilai kearifan lokal dalam pembelajaran generasi mudanya, meskipun hal ini akan berkonsekuensi munculnya beragam bentuk pembelajaran dalam tingkat praktis.

Pendidikan berbasis kearifan lokal adalah pendidikan yang mengajarkan peserta didik untuk selalu dihadapkan dengan situasi konkret. Hal ini sebagaimana Paulo Freire, menyebutkan dengan dihadapkannya pada problem dan situasi konkret 
yang dihadapi, peserta didik akan semakin tertantang untuk menanggapinya secara kritis. Oleh karena itu di perlukan adanya integrasi ilmu pengetahuan dengan kearifan lokal[13]

Hasil observasi dan diskusi yang dilakukan terhadap beberapa guru dan kepala sekolah di SMPN di Kabupaten Solok Selatan, dalam pembelajaran guru-guru belum menggunakan beragam bahan ajar yang dapat mengakomodasi fakta dari kondisi keseharian siswa. Disamping itu pembelajaran yang dilakukan oleh guru-guru umumnya masih belum menggunakan media pembelajaran yang kontekstual. Hal ini disebabkan karena kompetensi yang dimiliki guru-guru dalam merancang dan mengembangkan bahan ajar pembelajaran masih rendah, walaupun kenyataannya banyak jenis dan ragam fakta di sekitar siswa yang dapat ditemukan, dikembangkan dan dimanfaatkan untuk menunjang pembela-jaran.

Berdasarkan keadaan tersebut maka tim akan membantu guru-guru SMPN di Kabupaten Solok Selatan untuk meningkatkan kemampuannya khususnya dalam mengembangkan bahan ajar melalui kajian konsep IPA berbasiskan kearifan lokal.

\section{Materi dan Metodologi}

\section{A. Materi}

Guru yang profesional adalah guru yang dapat merancang skenario pembelajaran dengan baik melalui pemilihan metode serta penggunaan media pembelajaran yang beragam yang saling bersinergi dengan peserta didik untuk menghasilkan pembelajaran yang bermakna. Kenyataan yang terjadi saat ini, masih banyak guru yang tidak optimal dalam merencanakan dan menyiapkan perangkat pembelajaran atau menyusun skenario pembelajaran.

Sesuai dengan Permendikbud No. 70 Thn 2013 dalam kegiatan pembelajaran harus dilakukan perubahan dari pola pembelajaran satu arah (interaksi guru-peserta didik) menjadi pembelajaran interaktif (interaktif guru-peserta didik-masyarakat-lingkungan alam, sumber/media lainnya), pola pembelajaran pasif menjadi pembelajaran aktif. Pada kegiatan pembelajaran guru dituntut untuk menggunakan bahan ajar, media pembelajaran yang bervariasi, sehingga guru dapat mengembangkan pembelajaran ke arah yang lebih dinamik dan bermutu.

Jadi dalam pembelajarannya guru hendaknya dapat mengkaitkan materi yang dipelajari dengan kondisi lokal/ kearifan lokal daerah tersebut. Untuk itu guru dapat menganalisis konsep materi IPA tersebut berbasiskan kearifan lokal. Dalam kearifan lokal terkandung prinsip lokalitas, yakni setiap daerah memiliki nilai-nilai kearifan masingmasing. Strategi pembelajaran yang baik hendaknya berangkat dari keberagaman ini. Setiap daerah wajib menempatkan nilai kearifan lokal dalam pembelajaran generasi mudanya, meskipun hal ini akan berkonsekuensi munculnya beragam bentuk pembelajaran dalam tingkat praktis.

Pendidikan berbasis kearifan lokal adalah pendidikan yang mengajarkan peserta didik untuk selalu konkret dengan apa yang mereka hadapi.

\section{Metodologi}

Agar solusi ini dapat direalisasikan kepada mitra yaitu guru-guru IPA di SMP Kabupaten Solok Selatan, maka metode yang digunakan terdiri dari beberapa langkah yaitu. Pertama persiapan, langkah ini dilakukan diskusi dengan guru-guru untuk mengidentifikasi/mengkaji konsep-konsep IPA dan orientasi dengan kearifan lokal, dan didiskusikan teknik, jadwal kegiatan bersama mitra. Kedua pelaksanaan, pada kegiatan ini mitra diberikan pengetahuan melalui pendampingan tentang bahan ajar, menganalisis konsep-konsep IPA berbasis kearifan lokal, tentang media pembelajaran. Setelah diberi pengetahuan, para mitra (guru-guru) akan diberi pendampingan dalam mengembangkan bahan ajar melalui kajian 
konsep IPA berbasis kearifan lokal. Ketiga monitoring dan evaluasi, pada langkah ini dilakukan pendampingan dalam bentuk monitoring dan evaluasi atas pelaksanaan kegiatan program kemitraan ini. Kegiatan ini dilakukan bersamasama oleh tim pengusul dan mitra. Ke empat analisis data dan pembuatan laporan

\section{Hasil dan Diskusi}

\section{A. Hasil}

Sesuai dengan tujuan PKM ini, pertama memberikan wawasan tentang pengembangan bahan ajar, diskusi tentang konsep-konsep IPA dan wawasan tentang kearifan lokal. Ke dua melakukan diskusi dan pembimbingan pengembangan bahan ajar berbasikan kearifan lokal.

Berdasarkan analisis data hasil pretest dan postest dari guru-guru yang melaksanakan pretest dan postest (yang mengumpulkan lembaran jawaban) kedua test. Pengujian menggunakan SPSS 20, diperoleh deskripsi dari kedua data seperti pada Tabel 2

Tabel 2. Descriptive Statistics

\begin{tabular}{lccccc}
\hline & N & $\begin{array}{c}\text { Mini } \\
\text { mum }\end{array}$ & $\begin{array}{c}\text { Maxi } \\
\text { mum }\end{array}$ & Mean & $\begin{array}{c}\text { Std. } \\
\text { Deviati } \\
\text { on }\end{array}$ \\
\hline Pretest & 13 & 33,30 & 80,00 & 55,14 & 12,35 \\
postest & 13 & 46,70 & 93,30 & 67,18 & 14,52 \\
\hline
\end{tabular}

Dari Tabel 2. bahwa nilai pretest rata-rata adalah 55,14 dengan nilai minimum adalah 33,30 dan nilai maksimum 80,00 . Nilai posttest rata-rata adalah 67,18 dengan nilai minimum adalah 46,70 dan nilai maksimum 93,30. Jadi nilai rata-rata, postest lebih tinggi dibandingkan dengan nilai pretest.

Untuk membandingkan hasil ujian pretest dengan hasil postest dari peserta maka terlebih dahulu dilakukan uji normalitas data. Hasil normalitas data dapat dilihat pada Tabel 3.

Tabel 3. Hasil Uji Normalitas Data

\begin{tabular}{lrrr}
\hline & \multicolumn{3}{c}{ Shapiro-Wilk } \\
& Statistic & df & \multicolumn{1}{c}{ Sig. } \\
\hline Pretest &, 974 & 13 &, 933 \\
Postest &, 945 & 13 &, 524 \\
\hline
\end{tabular}

Berdasarkan hasil analisis pada Tabel 3 diperoleh hasil pretest dengan signifikasi 0,933 > 0,05 kelompok data berdistribusi normal dan untuk data postest dengan signifikansi 0,524 >0,05 data juga berdistribusi normal. Selanjutnya dilakukan uji homogenitas seperti pada Tabel 4.

Table 4. Test of Homogeneity of

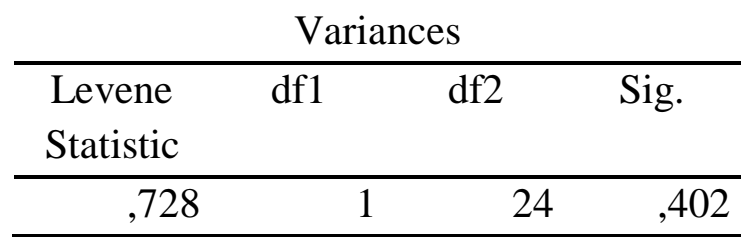

Dari Tabel 4, diperoleh nilai signifikansi $0,402>$ 0,05 yang berarti data adalah homogen.

Selanjutnya untuk melihat perbedaan dari hasil pretes terhadap postes dilakukan dilakukan uji $\mathrm{t}$ berpasangan. Hasil analisis dapat dilihat pada Tabel 5.

Tabel 5. Paired Samples Test

\begin{tabular}{rrrrr}
\hline & t & df & $\begin{array}{c}\text { Sig. (2- } \\
\text { tailed) }\end{array}$ \\
\hline Pair $1 \begin{array}{c}\text { Pretest } \\
\text { Postest }\end{array}$ & $-2,603$ & 12 &, 023 \\
\hline
\end{tabular}

Tabel 5. Menunjukkan hasil signifikansi $0,023<$ 0,05, Jadi dapat diambil kesimpulan bahwa terdapat perbedaan antara hasil pretes dengan postes. Dimana nilai rata-rata postest lebih tinggi dari nilai rata-rata pretest Tabel 2, ini menunjukkan bahwa terdapat peningkatan kompetensi guru-guru dalam pengembangan kajian konsep IPA berbasis kearifan lokal. Seperti terlihat pada Gambar 3. 


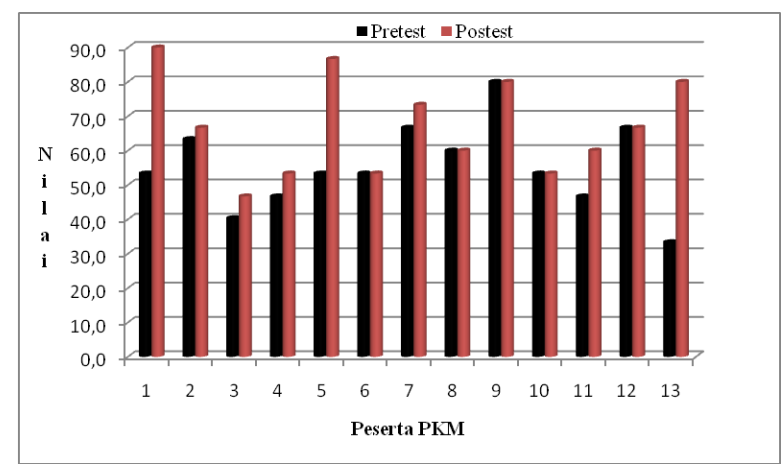

Gambar 1. Nilai Pretest dan Postest Berdasarkan hasil angket tentang respon peserta terhadap kegiatan PKM, semua peserta menyatakan kegiatan pelatihan ini dapat meningkatkan kompetensi guru, sehingga akan dapat membuat setiap peserta didik berpartisipasi aktif dalam proses pembelajaran.

Juga telah dihasilkan bahan ajar berupa LKPD, berbasiskan kearifan lokal.

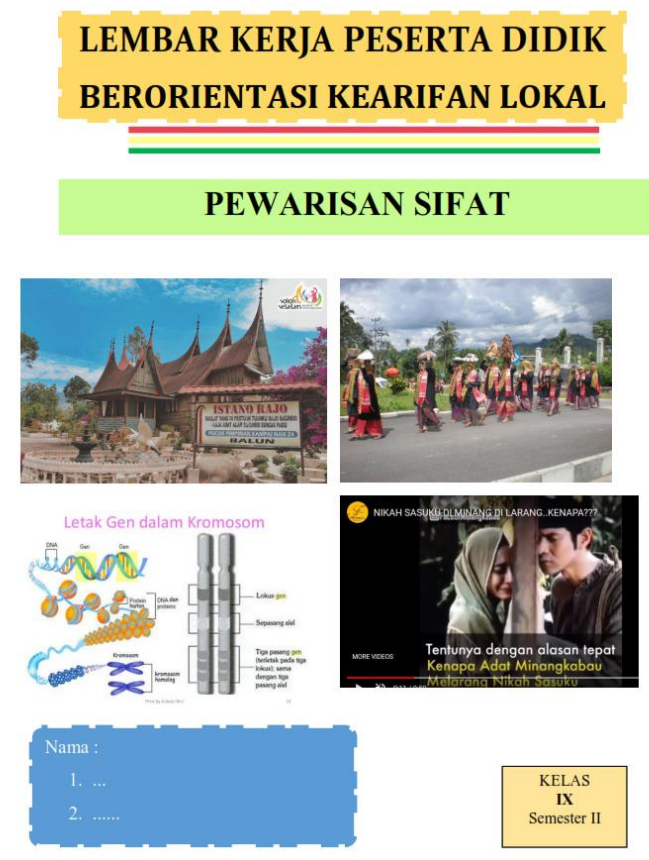

Gambar 2. Contoh LKPD

B. Pembahasan

Dari analisis data hasil pretest dan hasil postest, diperoleh peningkatan nilai rata-rata dari pretest yaitu 55,14 menjadi 67,18 pada postest. Jadi nilai rata-rata, postest lebih tinggi dibandingkan dengan nilai pretest. Dari uji paired $t$ test, diperoleh hasil signifikansi $0,023<0,05$, dengan demikian dapat disimpulkan bahwa terdapat peningkatan kemampuan guru-guru dalam mengembangkan bahan ajar melalui kajian konsep IPA berbasis kearifan lokal.

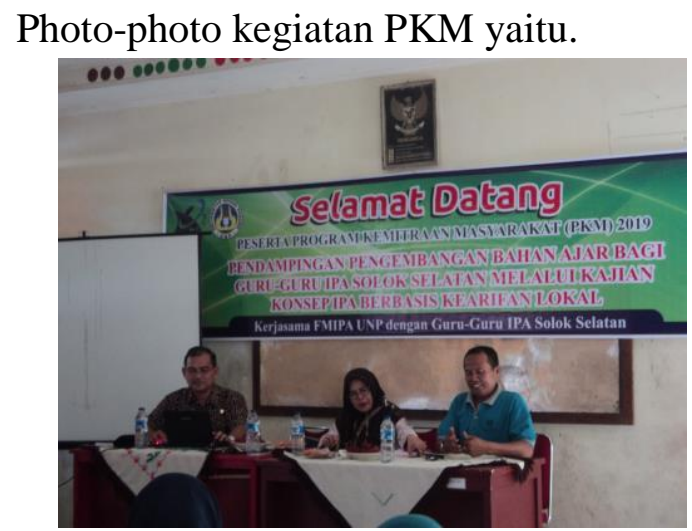

Gambar 3. Bpk Kepala sekolah SMP 1 Solok Selatan dan Pengawas Mata Pelajaran IPA memberikan sambutan pembukaan pendampingan kepada Guru-Guru

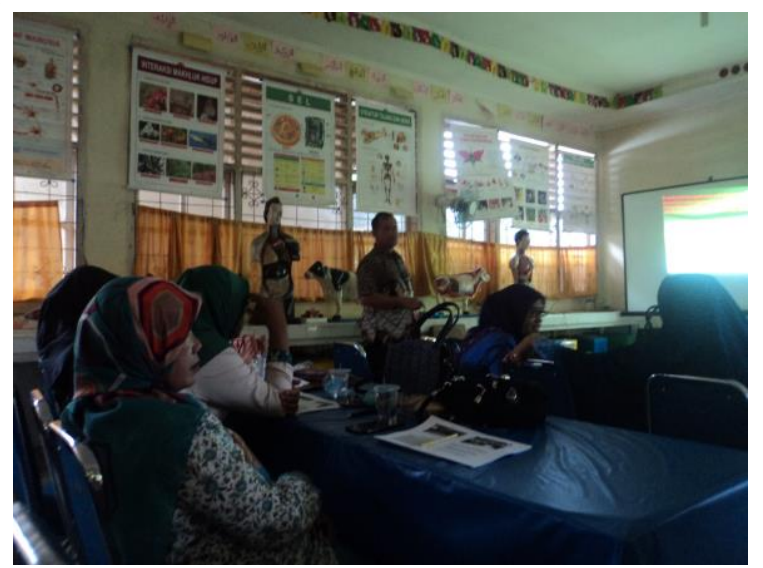

Gambar 4. TIM PKM sedang memberikan materi kepada Guru-Guru

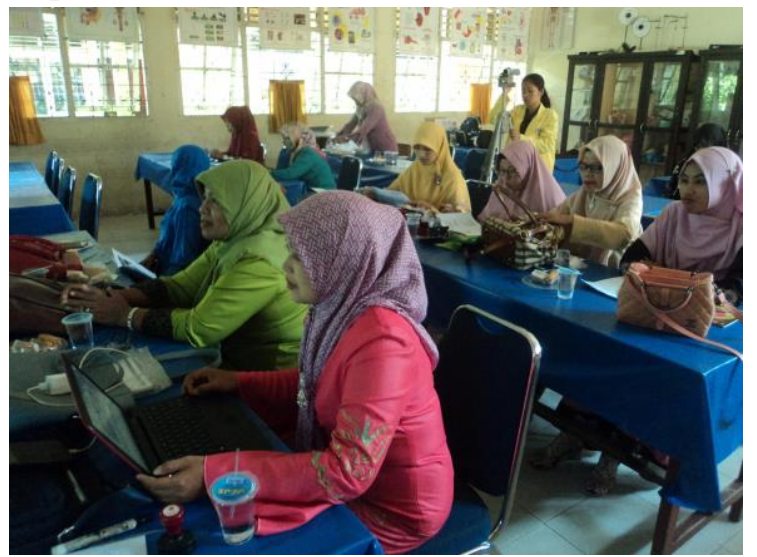


Gambar 5. Peserta serius mencoba merancang bahan ajar berdasarkan kajian konsep IPA berbasiskan Kearifan lokal.

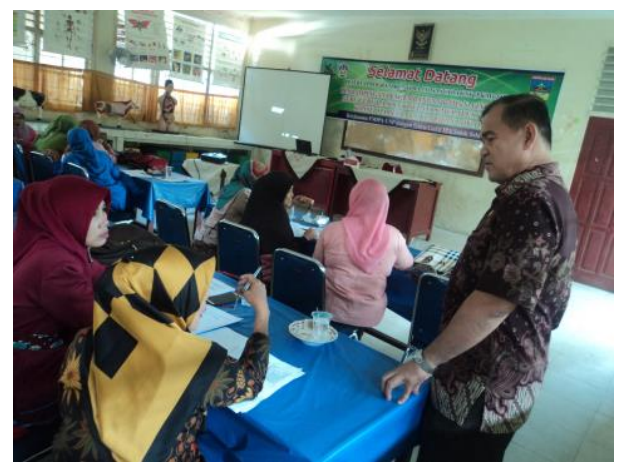

Gambar 6. Tim PKM mendampingi peserta dalam pengembangan bahan ajar

\section{Simpulan}

Berdasarkan analisis dari hasil evaluasi yang telah dilakukan sampai tahap yang dilakukan dapat diambil beberapa kesimpulan :

1. peningkatan kemampuan guru-guru dalam mengembangkan bahan ajar melalui kajian konsep IPA berbasis kearifan lokal.

2. Kegiatan pelatihan ini juga sudah menghasilkan multimedia yang digunakan guru dalam kegiatan pembelajarannya

\section{UCAPAN TERIMA KASIH}

Terima kasih kami sampaikan kepada Menristek Dikti dan Rektor UNP serta Ketua LP2M UNP yang telah telah mendanai kegiatan PKM ini melalui dana DRPM tahun 2019.

\section{Daftar Pustaka}

[1] https://id.wikipedia.org/wiki/Kabupaten $\underline{\text { Solok_Selatan }}$ (diakses 12 Agustus 2018)

[2] www.lpdp.kemenkeu.go.id/wp-content/ uploads/2015/.../Daftar-Daerah-3T2015.pdf (diakses 12 Desember 2016)
[3]

https://sumbar.bps.go.id/dynamictable /2016/10/05/23/indeks-pembangunanmanusia-ipm-provinsi-sumatera-barat2010-2017-metode-baru-.html (diakses 12 Agustus 2018)

[4] http://batamnews.co.id/berita-10924-fotofotodahsyatnya-banjir-dan-longsor-di-solokselatan-sumbar.html (diakses 12 Agustus 2018)

[5]

http://redaksisumbar.com/solok-selatanoptimis-tahun-2019-keluar-dari-statusdaerah-tertinggal/ (diakses 16 April 2017)

[6] https://puspendik.kemdikbud.go.id/hasil -un/ ( diakses 23 Juni 2017)

[7] Permendikbud. 2014. Lampiran Peraturan Menteri Pendidikan dan Kebudayaan RI Nomor 103 Tahun 2014 tentang Pedoman Pelaksanaan Pembelajaran. Jakarta: Kementerian Pendidikan dan Kebudayaan. 
[8] Hufri, (2017), Pengembangan Bahan Ajar Fisika Berbasiskan Kontekstual Pada Pembelajaran Quided Inquiry Untuk Kelas XI SMA/MA, Prosiding Semirata 2017 Bidang MIPA BKS-PTN Wilayah Barat 2. Universitas Jambi, hal. 13121321

[9] Sari Silvi Yulia, Hufri, Wahyuni Satria Dewi, 2018, Pelatihan Pengembangan Multimedia Berbasiskan Kontekstual Untuk Pembelajaran Inquiry Bagi GuruGuru SMPN 19 dan SMPN 34 Kabupaten Solok Selatan, Pelita Eksakta 1 (vol 2), 102-107

[10] Hufri, Letmi D, Harman A, (2018). Peningkatan Kompetensi Pedagogik Guru-Guru IPA SMP Solok Selatan Melalui Pendampingan Implementasi Pembelajaran Kontekstual Berdasarkan Pendekatan Saintifik, Pelita Eksakta 1 (vol 2), 108-112

[11] Hufri, Harman Amir, Mona TC, Silvia I, Naimis S H. (2018). Peningkatan Kompetensi Guru-Guru SMP_Solok Selatan Melalui Pelatihan Pengembangan Media Pembelajaran Berbasis Kontekstual Dengan Pendekatan Saintifik. Pelita Eksakta 1 (vol 1), 37-42

[12] Hufri, Silvi Y S, Naimis S H, Silvia I, (2019). Improvement of Teacher Capability in Solok Selatan District in Developing Multimedia Through Training Video Editing, Pelita Eksakta 2 (vol 1), 41-47

[13] Paulo Freire, 2000, Cultural Action for Freedom, 2000 Edition, Harvard Educational Review and Center for the Study of Development and Social Change. 